\title{
THE BALANCED SCORECARD (BSC) AS A SUPPORT TO THE CMMI-DEV CONSTELLATION SCAMPI FOR THE RECOGNITION OF THE MATURITY OF THE SOFTWARE PROCESS
}

\author{
Oswaldo Alfaro Bernedo \\ National University Federico Villarreal, (Perú). \\ E-mail: oalfaro@unfv.edu.pe ORCID: https://orcid.org/0000-0002-9803-5986 \\ Doris Esenarro \\ National University Federico Villarreal, (Perú). \\ E-mail: desenarro@unfv.edu.pe ORCID: https://orcid.org/0000-0002-7186-9614
}

Giro Rodriguez

National University Mayor de San Marcos, (Perú).

E-mail: crodriguezro@unmsm.edu.pe ORCID: https://orcid.org/0000-0003-2112-1349

Maria Rene Alfaro

National University Federico Villarreal, (Perú).

E-mail: mralfaro@unfv.edu.pe ORCID: https://orcid.org/0000-0003-4601-6748

Recepción: 01/09/2020 Aceptación: 07/10/2020 Publicación: 13/11/2020

Gitación sugerida Suggested citation

Alfaro, O., Esenarro, D., Rodriguez, C., y Rene, M. (2020). The balanced scorecard (BSG) as a support to the CMMI-DEV constellation SCAMPI for the recognition of the maturity of the software process. 3C Tecnología. Glosas de innovación aplicadas a la pyme. Edición Especial, Noviembre 2020, 33-49. https://doi. org/10.17993/3ctecno.2020.specialissue6.33-49 


\section{ABSTRACT}

This research tries to establish the degree of influence exerted by the design and use of a Balanced Scorecard (BSC), as a support to the Standard CMMI Appraisal Method for Process Improvement SCAMPI of the CMMI-DEV constellation, in recognition of the level of maturity of the software process, due to the efficiency and effectiveness provided by its application in practical life. In addition, it uses the Systemic Approach to conceive the problem comprehensively, under a holistic perspective, covering the relationships of each element within the system and its relationships with external agents; the applied methodology consists in the collection, tabulation, and analysis of the antecedents that have been obtained for its direct validation during development, that is, the management of cause-effect variables, where the independent or experimental variable is of interest to the researcher because the variable that is hypothesized $(\mathrm{X})$, is one of the causes that produce the supposed effect. As a result of the effectiveness of the SCAMPI evaluation process, going from $72.7 \%$ to $92.7 \%$; This is equivalent to a $26.4 \%$ improvement in performance, increasing from 10.9 correct evaluations to 13.9 for conducting such evaluations.

\section{KEYWORDS}

Balanced scorecard, Support, Constellation, SCAMPI, Maturity of the software. 


\section{INTRODUCTION}

In its research to help organizations develop and maintain quality products and services, the Software Engineering Institute (SEI) has found several dimensions that an organization can focus on to improve its business. Also, it illustrates the three fundamental dimensions on which organizations usually focus: people, procedures and methods, and tools and equipment. This virtuous circle involving these components is key to achieving a quality product (2GC Active Management, 2019).

Software, understood in its duality of process and product, is inherently problematic; such complexity is manifested in many aspects, the most relevant being: the fact of being intangible, difficulty in delimiting the scope or domain, diversity of languages to express it in semantic and notational form, frequent changes in business rules that attempt against its functional validity and, consequently, the predominance of accelerated product obsolescence, etc.

The CMMI has two structures of Representations, the same ones that give rise to two different types of evaluations. Figure 1 illustrates the structure of the Representations Continuous. The differences between the structures of Figure 1 and the Staged representation are subtle but significant. The staged picture uses maturity levels to characterize the overall state of the organization's processes concerning the model. In contrast, the continuous representation uses capability levels to characterize the state of the organization's processes concerning an individual process area. This dimension (the capability/maturity dimension) of CMMI is used for benchmarking and assessment activities, as well as to guide an organization's improvement efforts (Álvarez, 2016).

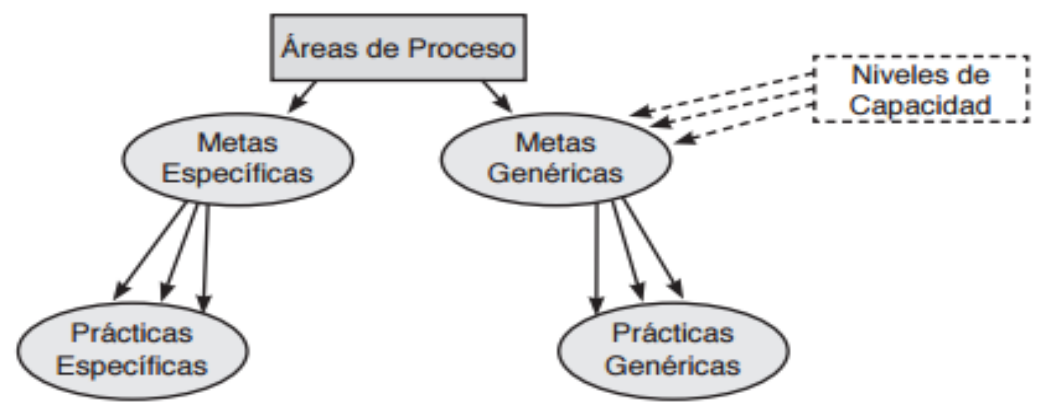

Figure 1. Continuous representation. 
As show in Figure 1, capacity levels refer to the achievement of process improvement in an organization in individual process areas. These levels are a means of incrementally improving the processes that correspond to a given process area.

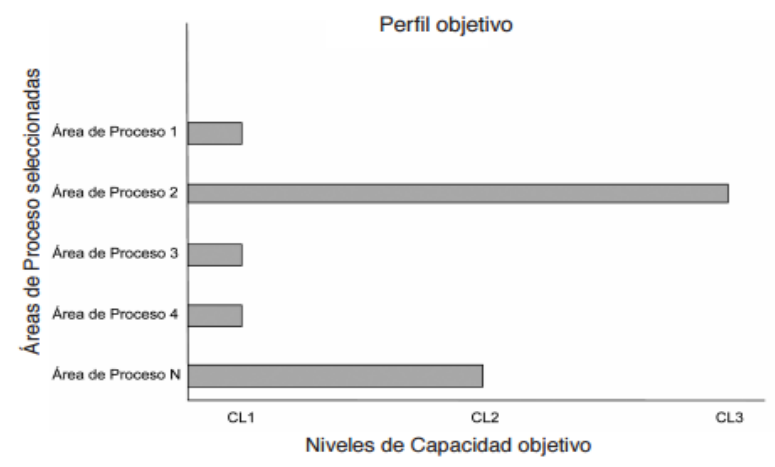

Figure 2. The four levels of capability are numbered from 0 to 3 .

Maturity levels, on the other hand, refer to the achievement of process improvement in an organization in multiple process areas. These levels are a means of improving processes for a given set of process areas (i.e., maturity level). As illustrated in the Figure 2, the five maturity levels are numbered from 1 to 5 .

There is a dependency or causal relationship between Strategic Planning and the BSC, i.e., the formulation of the strategic plan is the primary input of the latter, so when designing and operating the BSC, this condition should not be lost sight of. In this regard, the structure of the strategic plan under the BSC approach has the following structure (De Flander, 2018):

a) Institutional: where the values, role, and scope of the institution are stated; the philosophy of the institution; the expectations of related agents or interest groups.

b) Strategic Management: a segment in which the Mission, Vision, and General Strategic Objectives and Specific Strategic Objectives for the established time horizon are formally expressed.

c) Related strategies: the set of actions to be deployed to achieve the formulated objectives.

d) Management indicators: sets of metrics to measure the institution's functional performance. 
The following table shows in a structured way the perspectives, general objectives, specific objectives, and corresponding indicators that are part of a corporate strategic plan.

The BSC is configured in four hierarchically aligned perspectives under a causal alignment. This structure responds to the logic of the so-called strategic map, which in turn is constituted by the causal relationship of the strategic objectives derived from the institutional strategic plan. The perspectives considered are financial, commercial, internal processes, and learning; each one of them, in turn, is made up of strategic objectives, indicators, and goals.

The BSC is used as a strategic management model, a communication tool, and, in its best implementations, an organizational change tool. This management model is based on a basic principle stated as "you can only manage what you can measure" (Lamé, Jouini \& Stal-Le Cardinal, 2019).

The BSC is a tool that translates strategy into action. BSC is a performance planning and management model that places strategy at the center of the process. The applicability of the BSC has no limits of any nature because being a comprehensive management measurement system can be adapted to any organization, for tangible or intangible processes, for large or small organizations, public or private.

There is a wide variety of software tools to implement and automate the operation of this important strategic management tool. However, there is one that, taking the institutional strategic plan as a reference base, allows move towards management by indicators. This is the case of Sixtina BSG, whose flexibility, robustness, and user-friendliness allow for relatively easy incorporation of the designed strategic matrix into the strategic plan.

The software organizes the management indicators in a structured manner. The highest hierarchy is General Compliance, then Critical Factor, then Indicator, and finally, Data. This structure is causal, i.e., the sequencing starts from the Learning perspective, then Internal processes, Customers, and Financial. The person responsible for designing the BSC assigns the weighted weights to each of the management indicators.

The BSC dashboard shows in the second column, the performance status of each indicator in the chromatic form: green means satisfactory, yellow is equivalent to alert, and red indicates deficient. The next column shows the actual value of each indicator; this 
information is extracted from the database of the institution's information system; then it shows the measure of the expression of each indicator, corresponding points for general compliance, critical factor, and indicator; instead, for data, it corresponds to the measure corresponding to its nature. The columns follow it for the date, operation (maximize, minimize or stabilize), perspectives already indicated, the person responsible for the results achieved by each indicator; the weighted weight (\%) in determining the formula for the compound indicators, the trend, the target value defined, the deviation observed between the actual value and the target, the origin of the data (formula, manual, database, Excel) and finally the frequency of recording the information (daily, weekly, monthly or annual) (Catchpole et al., 2017).

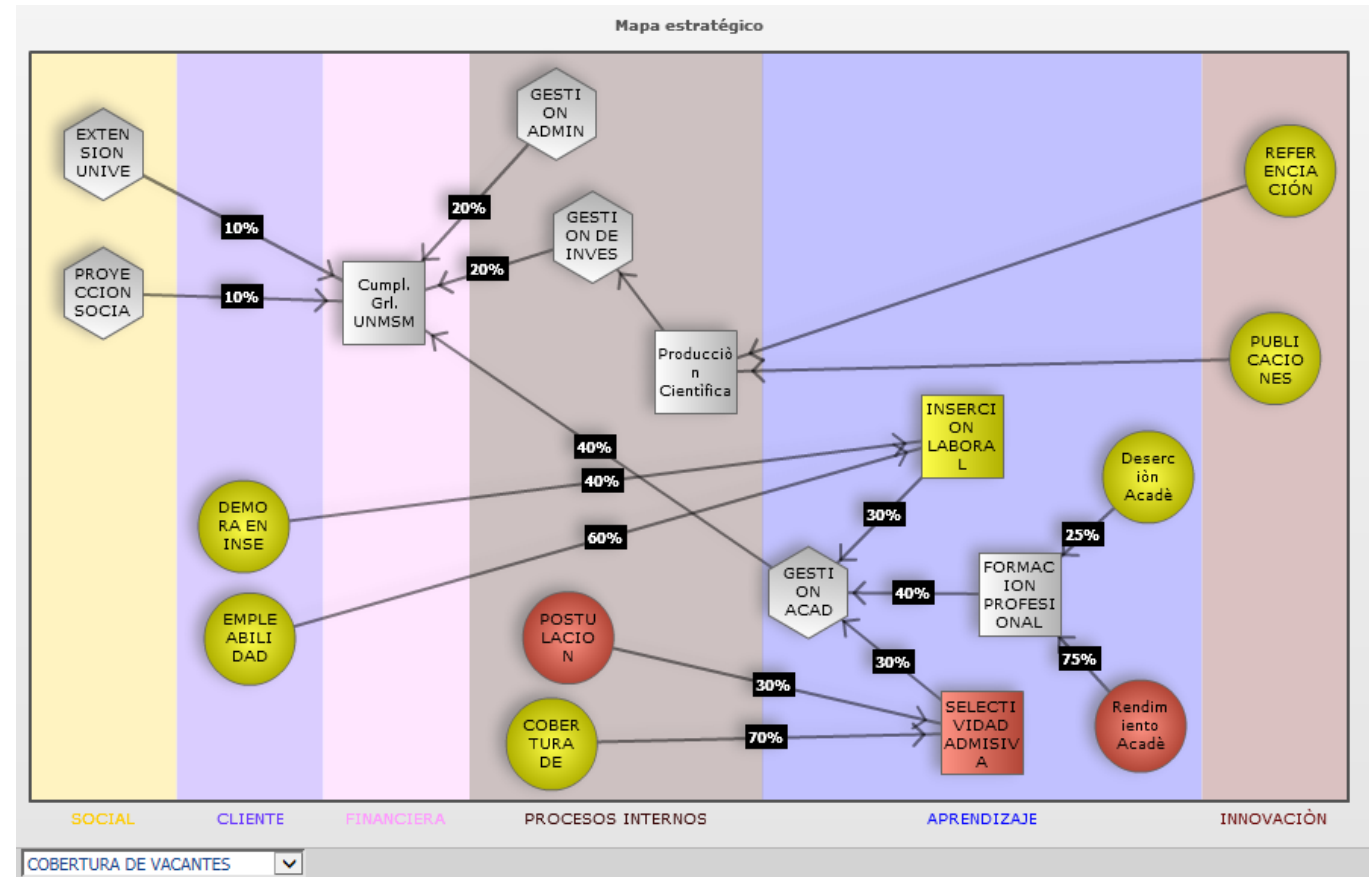

Figure 3. BSCS strategic Map.

Figure 3 shows the strategic map corresponding to the BSC scorecard, whose purpose is to articulate in a systemic, causal, hierarchical, transversal, and weighted way all the management indicators. This view is very important for the stakeholders because, in one single view, the interaction of the indicator system can be understood. 


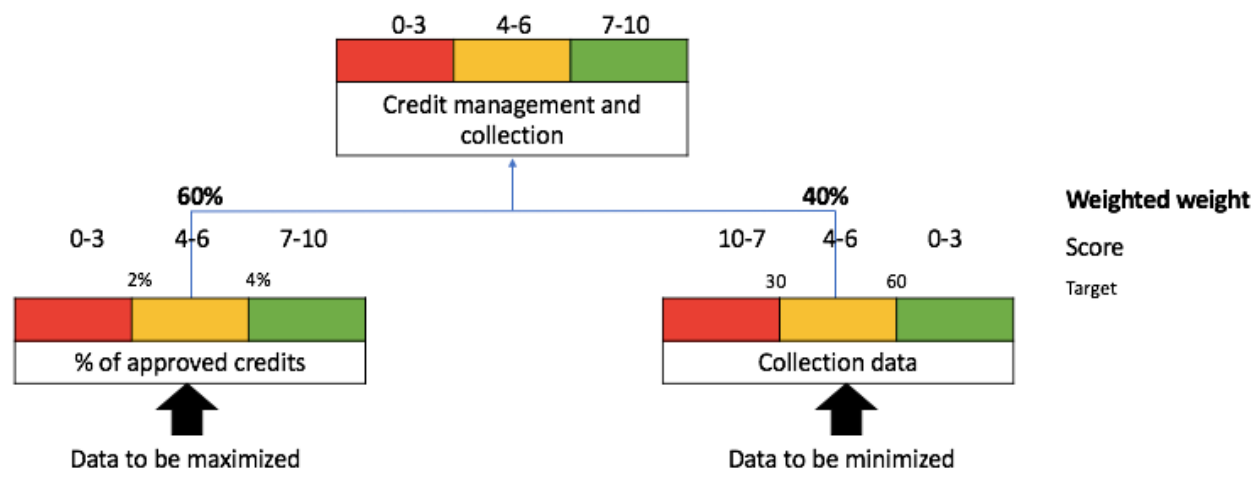

Figure 4. Homogenization of heterogeneous indicators.

The calculation and color representation of each of the indicators in the BSC control panel is shown in Figure 4. The sequence is bottom-up, i.e., based on data of a heterogeneous nature, quantity, orientation, and weighting, using the corresponding formula, the resulting indicators of a homogeneous nature are determined in units of measurement (points) and orientation (maximize). To determine the values of the critical factors and general compliance, the same procedure is followed as above (Institute and Faculty of Actuaries, 2019).

Table 1. Parameterization and import of information in BSC Sixtina.

\begin{tabular}{|c|c|c|c|c|c|}
\hline SERIES & DETAIL & \multicolumn{3}{|c|}{ DATA } & $\begin{array}{l}\text { GENERAL COMPLIANCE, } \\
\text { CRITICAL FACTOR OR } \\
\text { INDICATOR }\end{array}$ \\
\hline \multirow{3}{*}{ REAL } & Operation & Maximize & Minimize & Stabilize & Maximize \\
\hline & Capture & \multicolumn{3}{|c|}{ excel import - databases } & $\begin{array}{c}\text { formula (rank/average index } \\
\text { children) }\end{array}$ \\
\hline & Magnitude & \multicolumn{3}{|c|}{ original size } & score (0 to 10$)$ \\
\hline \multirow{3}{*}{ ALARM } & Operation & Maximize & Minimize & Stabilize & Maximize \\
\hline & Capture & \multicolumn{3}{|c|}{ excel - manual } & excel - manual \\
\hline & Magnitude & \multicolumn{3}{|c|}{ original size } & score $(0$ to 10$)$ \\
\hline \multirow{3}{*}{ OBJECTIVE } & Operation & Maximize & Minimize & Stabilize & Maximize \\
\hline & Capture & \multicolumn{3}{|c|}{ excel - manual } & excel - manual \\
\hline & Magnitude & \multicolumn{3}{|c|}{ original size } & score (0 to 10$)$ \\
\hline
\end{tabular}

\section{Maximize}

\begin{tabular}{|c|c|c|}
\hline \multicolumn{3}{|c|}{ Fees } \\
\hline 0 & \multicolumn{2}{|c|}{ Max } \\
\hline Deficiency & Alarm & Target \\
\hline
\end{tabular}




\section{Minimize}

\begin{tabular}{|c|c|c|}
\hline \multicolumn{3}{|c|}{ Fees } \\
\hline 0 & & Max \\
\hline Target & Alarm & Deficiency \\
\hline
\end{tabular}

\section{Stabilize}

\begin{tabular}{|c|c|c|c|c|}
\hline \multicolumn{5}{|c|}{ Fees } \\
\hline 0 & & & & Max \\
\hline Default default & Lower alarm & Target & Higher alarm & $\begin{array}{l}\text { Deficiency due } \\
\text { to excess }\end{array}$ \\
\hline
\end{tabular}

Table 1 is a summary of the information processing for the construction of the BSC control panel content. For each series (actual, alarm or target), depending on the type of indicator, operations are performed (maximize, minimize or stabilize) as appropriate; information capture is defined (import from Excel or database, Excel or manual); also, the magnitude (points or original magnitude of the data) is established. Likewise, the dimensions for the three operation options of the indicators and their corresponding color are defined.

Since the CMMI, SCAMPI, and BSC models have been characterized integrally, by the research objective, it has been possible to establish an analogy between the SCAMPI evaluation process and the BSC control panel. As shown in Table 2, it is possible to equate the hierarchical levels of maturity assessment of SCAMPI and the performance of the management indicators of the Sixtina BSC scorecard.

Table 2. Equivalences between SCAMPI model and Sistine BSC.

\begin{tabular}{|c|c|}
\hline SCAMPI Maturity Assessment Model & BSC control panel model \\
Maturity level & General compliance \\
\hline Process area & Critical factor \\
Goals & Indicator \\
Internship & Fact \\
\hline
\end{tabular}

The convenience of applying the BSC as a tool to facilitate the SCAMPI evaluation of the CMMI-DEV constellation, oriented to the recognition of the software process maturity level, is supported by the following reasons. 


\section{METHOD}

This research work is based on the Scientific Research Method due to the efficiency and effectiveness provided by its application in practical life. Furthermore, it uses the Systemic Approach to conceive the problem integrally, under a holistic perspective, covering the relations of each element within the system and its relations with external agents.

Consequently, the project is following a proven method of collecting, tabulating, and analyzing the background that has been obtained and proving its validity directly in the field in which the research fact is being presented (Borchert, Schirmeier \& Spinczyk, 2017).

The design of the Experimental Research has been selected, that is to say, the handling of variables of the cause-effect type, where the independent or experimental variable is of interest to the researcher because the variable that is hypothesized $(\mathrm{X})$ is one of the causes that produce the supposed effect (Denicolai \& Previtali, 2020).

The design is quasi experimental, allows the use of pre-tests and post-tests to analyze the evolution of the effect of the "pilot" implementation before and after the experimental treatment so that the subtype of Research design used is: "Post-test design and control group", whose general model is shown below:

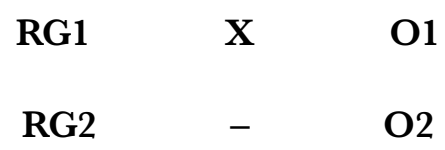

Where:

RG1 = Experimental Group (formed randomly by software process evaluations for recognition of maturity levels using the $\mathrm{BSC}$ )

RG2 = Control group (formed randomly by software process evaluations for recognition of maturity levels in the absence of the stimulus)

$\mathbf{X}=$ Stimulation $($ El Balanced ScoreCard $)$

- = Absence of Stimulus

$\mathbf{O} 1, \mathbf{O} 2$ = Measurement of maturity level indicators 
This design includes two groups, one receiving the experimental treatment (Experimental Group) and the other not (Control Group). That is, the manipulation of the independent variable reaches only two levels (presence and absence).

- Materials:

- CMMI-DEV Constellation

- SCAMPI model

- Software development processes

- Balanced Score Card Software

- Procedure:

1. Business processes that have been automated through software development processes are identified.

2. The development constellation of the CMMI model is characterized.

3. Requests for evaluation of CMMI-DEV maturity levels are received.

4. The evaluation team is constituted, designating the leader.

5. The Balanced Score Card logic model applied to the SCAMPI model is built.

6. An evaluation or audit is carried out to recognize the level of maturity required.

7. The results of the evaluations are compared

8. The results are interpreted.

9. The hypotheses are verified.

\section{RESULTS}

By the objective of the research, the hypothesis, the design, and the procedure that has been applied in this investigation, initially, a company has been characterized as a prototype, which constitutes the control group to which the BSC was not applied in the SCAMPI evaluation process, for the recognition of the level of maturity of the software process implemented in that organization, that is, maintaining its original conditions of structure and operation. Then, the prototype was made for a SCAMPI evaluation of maturity level 2, using the BSC, whose software corresponds to Sixtina BSC. Specifically, the following procedure has been followed. (Brocklesby, 2016). 
1. The MWC-SCAMPI metamodel logic has been constructed to understand the scope and reach of the entities included in this integral process. This model has been designed with a view to the subsequent generation of the physical database (PIIDB), necessary to import the information from the Sistine BSC.

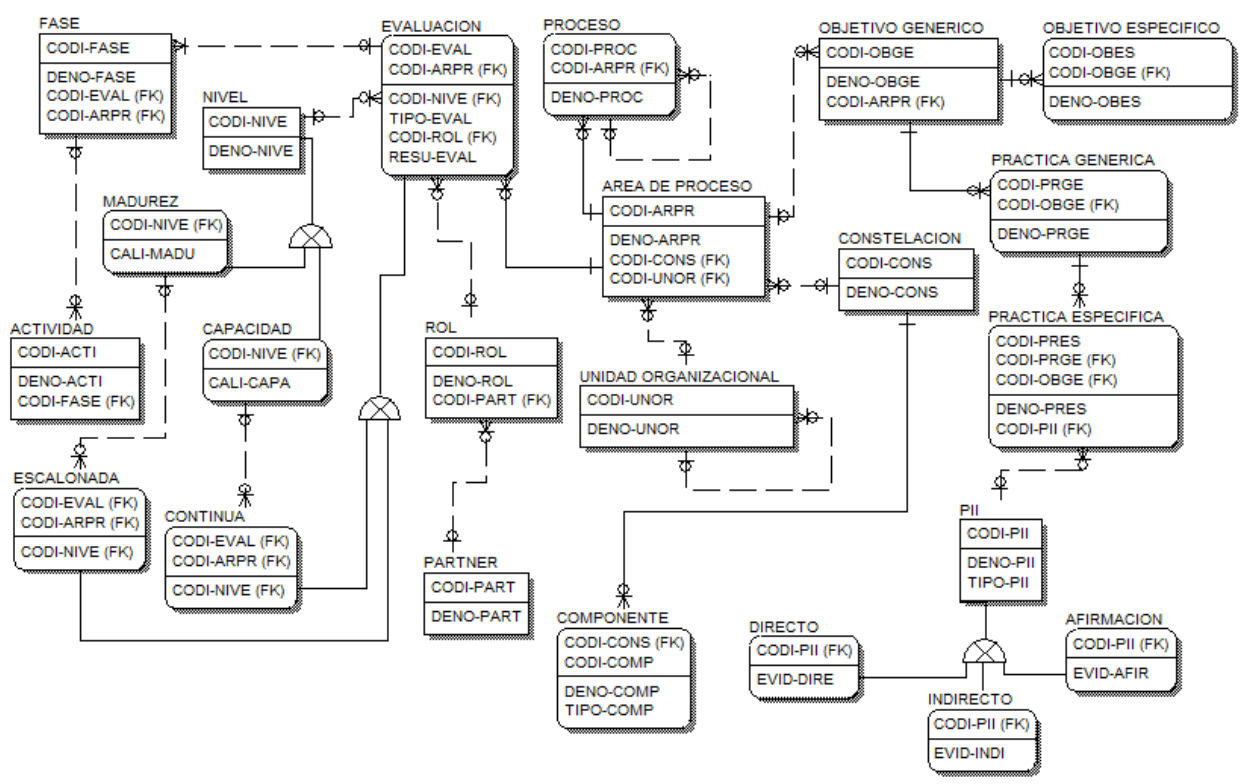

Figure 5. Logical metamodel CMMI SCAMPI.

Figure 5 shows all the entities, relationships, and attributes that are most prominent in this metamodel. Recursive relationships and sub-entities are also identified.

1) Advanced engineering has been carried out for the generation of the database (PIIDB) corresponding to the entity-relationship model designed in the previous point.

2) The equivalence between the components of the GMMI-SCAMPI model and the BSC Sixtina control panel has been established, as shown in the following table. It shows the relevance of establishing similar and, therefore, comparable hierarchies at the corresponding levels.

This analogy constitutes the full support to the proposal of this research project to use the Balanced Scorecard (BSG), as a support to the SCAMPI of the CMMI-DEV constellation, in recognition of the maturity level of the software process. 
1) Using the software BSC Sixtina under the web environment, the SCAMPI evaluation model of the CMMI development constellation (DEV) has been characterized.

2) In the same BSC board, the evaluation corresponding to maturity level 2 for the Process and Product Quality Assurance (PPAQ) process area, its four goals, as well as its 15 practices, has been carried out. I am applying for the SCAMPI protocol. With the information recorded in the database, the information has been contrasted, and the software has produced the color results observed, and, applying the decision rule of the SCAMPI protocol, the requested maturity level has not been reached as (Brocklesby, 2016) in an applied situation.

3) By way of simulation, the results of the research efficiency indicator have been measured. This metric expresses the time spent in carrying out a SCAMPI assessment, for maturity level 2, both for the control group (in the conventional form) and for the experimental group (using the BSC)

Table 3. Efficiency for the Control Group.

\begin{tabular}{|c|c|c|c|}
\hline \multirow{2}{*}{ EVALUATION } & \multicolumn{2}{|c|}{ DURATION (DAYS) } & \multirow{2}{*}{ EFFICIENCY } \\
\hline \multirow{2}{*}{ ESTIMATE } & REAL & \\
\hline 2 & 12 & 15 & $80.0 \%$ \\
\hline 3 & 10 & 14 & $71.4 \%$ \\
\hline 4 & 9 & 12 & $75.0 \%$ \\
\hline 5 & 10 & 15 & $66.7 \%$ \\
\hline 6 & 12 & 14 & $85.7 \%$ \\
\hline 7 & 10 & 15 & $66.7 \%$ \\
\hline 8 & 8 & 12 & $66.7 \%$ \\
\hline 10 & 14 & 18 & $77.8 \%$ \\
\hline AVERAGE & 12 & 16 & $75.0 \%$ \\
\hline DEVIATION & 14 & 16 & $87.5 \%$ \\
\hline
\end{tabular}


Table 4. Efficiency for the Experimental Group.

\begin{tabular}{|c|c|c|c|}
\hline \multirow{2}{*}{ EVALUATION } & \multicolumn{2}{|c|}{ DURATION (DAYS) } & \multirow{2}{*}{ EFFICIENCY } \\
\hline & ESTIMATE & REAL & \\
\hline 1 & 12 & 12 & $100.0 \%$ \\
\hline 2 & 10 & 11 & $90.9 \%$ \\
\hline 3 & 9 & 9 & $100.0 \%$ \\
\hline 4 & 10 & 15 & $66.7 \%$ \\
\hline 5 & 12 & 11 & $109.1 \%$ \\
\hline 6 & 10 & 11 & $90.9 \%$ \\
\hline 7 & 8 & 8 & $100.0 \%$ \\
\hline 8 & 14 & 15 & $93.3 \%$ \\
\hline 9 & 12 & 13 & $92.3 \%$ \\
\hline 10 & 14 & 13 & $107.7 \%$ \\
\hline AVERAGE & 11.10 & 11.80 & $95.1 \%$ \\
\hline DEVIATION & & & 0.12 \\
\hline
\end{tabular}

4) There is a substantial increase in the efficiency of the SCAMPI evaluation process, from $75.2 \%$ to $95.1 \%$; this is equivalent to a $26.4 \%$ improvement in performance, decreasing from 14.7 days to 11.8 days for such evaluation.

Table 5. Efficiency for the Control Group.

\begin{tabular}{|c|c|c|c|}
\hline \multirow{2}{*}{ EVALUATION } & \multicolumn{3}{|c|}{ PRACTICES } \\
\hline 1 & EVALUATED & ACCEPTED & EFFICACY \\
\hline 2 & 15 & 11 & $73.3 \%$ \\
\hline 3 & 15 & 10 & $66.7 \%$ \\
\hline 4 & 15 & 9 & $60.0 \%$ \\
\hline 5 & 15 & 13 & $86.7 \%$ \\
\hline 6 & 15 & 11 & $73.3 \%$ \\
\hline 7 & 15 & 11 & $73.3 \%$ \\
\hline 8 & 15 & 9 & $60.0 \%$ \\
\hline 9 & 15 & 12 & $80.0 \%$ \\
\hline 10 & 15 & 12 & $80.0 \%$ \\
\hline AVERAGE & 15 & 11 & $73.3 \%$ \\
\hline DEVIATION & 15.00 & 10.90 & $\mathbf{7 2 . 7 \%}$ \\
\hline
\end{tabular}


5) Also, by way of simulation, the results of the research effectiveness indicator have been measured. This metric expresses the degree of accuracy used in carrying out a SCAMPI assessment, for maturity level 2, for both the control group (in a conventional form) and the experimental group (using the BSC).

Table 6. Efficiency for the Experimental Group.

\begin{tabular}{|c|c|c|c|}
\hline \multirow{2}{*}{ EVALUATION } & \multicolumn{3}{|c|}{ PRACTICES } \\
\hline \multirow{2}{*}{ EVALUATED } & ACCEPTED & EFFICACY \\
\hline 2 & 15 & 14 & $93.3 \%$ \\
\hline 3 & 15 & 14 & $93.3 \%$ \\
\hline 4 & 15 & 15 & $100.0 \%$ \\
\hline 5 & 15 & 13 & $86.7 \%$ \\
\hline 6 & 15 & 14 & $93.3 \%$ \\
\hline 7 & 15 & 13 & $86.7 \%$ \\
\hline 8 & 15 & 13 & $86.7 \%$ \\
\hline 9 & 15 & 14 & $93.3 \%$ \\
\hline AVERAGE & 15 & 14 & $93.3 \%$ \\
\hline DEVIATION & 15 & 15 & $100.0 \%$ \\
\hline
\end{tabular}

There was a substantial increase in the effectiveness of the SCAMPI evaluation process as we can compare in tables 5 and 6 , from $72.7 \%$ to $92.7 \%$; this is equivalent to a $26.4 \%$ improvement in performance, increasing from 10.9 correct evaluations to 13.9 for conducting such evaluations.

\section{CONCLUSIONS}

The BSC is a powerful tool insofar as it is applied to follow up on performance reports.

Using the software BSG Sixtina under the web environment, the SCAMPI evaluation model of the CMMI development constellation (DEV) has been characterized.

As a result of the effectiveness of the SCAMPI evaluation process, going from $72.7 \%$ to $92.7 \%$; This is equivalent to a $26.4 \%$ improvement in performance, increasing from 10.9 correct evaluations to 13.9 for conducting such evaluations. 


\section{REFERENCES}

2GG Active Management. (2019). Balanced Scorecard Usage Survey 2018. Retrieved on August 30, 2019, from: https://2gc.eu/media/resource_files_survey_reports/2018_ Survey_Document_10_Final-compressed.pdf

Álvarez, I. (2016). FORBES. Retrieved on August 12, 2019, from: https://forbes.es/ listas/3865/las-diez-mejores-firmas-de-consultoria/

Borchert, G., Schirmeier, H., \& Spinczyk, O. (2017). Generic soft-error detection and correction for concurrent data structures. IEEE Transactions on Dependable and Secure Computing, 14(1),22-36. https://ieeexplore.ieee.org/document/7097670

Brocklesby,J. (2016). The what, the why, and the how of operational behavioral researchAn invitation to potential skeptics. European Fournal of Operational Research, 249(3), 796805. https://doi.org/10.1016/j.ejor.2015.09.034

Catchpole, K., Neyens, D.M., Abernathy, J., Allison, D., Joseph, A., \& Reeves, S.T. (2017). Framework for direct observation of performance and safetyin healthcare. BMJ Quality ES Safety, 26(12), 1015-1021. https://doi.org/10.1136/bmjqs-2016-006407

De Flander, J. (2018). Strategy Execution - The Definitive Guide - Feroen De Flander. Retrieved on August 24, 2019, from: https://jeroen-de-flander.com/strategy-execution/

Denicolai, S., \& Previtali, P. (2020) Precision Medicine: Implications for value chains and business models in life sciences. Technological Forecasting and Social Change, 151, page 1 19767. https://doi.org/10.1016/j.techfore.2019.119767

Institute and Faculty of Actuaries. (2019, October 7). RSS and IFoA publish new ethical guidance in data science. https://www.actuaries.org.uk/news-and-insights/news/rssand-ifoa-publish-new-ethical-guidance-data-science

Lamé, G., Jouini, O., \& Stal-Le Cardinal, J. (2019) Combining Soft Systems Methodology, ethnographic observation, and discrete-event simulation: A case study in cancer care. Fournal of the Operational Research Society, 71(10). https://doi.org/10.10 80/01605682.2019.1610339 
Ubalde, R., Rodriguez, C., Petrlik, I., Esenarro, D., Lezama, P., \& Sotomayor, J. (2020). Quality model for Peruvian microenterprises of a software product Factory. Test Engineering and Management, 83, 13434. 
3C Tecnología. Glosas de innovación aplicadas a la pyme. ISSN: 2254 - 4143 Edición Especial Special Issue Noviembre 2020 